Article

\title{
Optimization of Fe@Cu Core-Shell Nanoparticle Synthesis, Characterization, and Application in Dye Removal and Wastewater Treatment
}

\author{
Nkosinathi Goodman Dlamini ${ }^{1}{ }^{\mathbb{D}}$, Albertus Kotze Basson ${ }^{1}$, \\ Shandu Jabulani Siyabonga Emmanuel ${ }^{1}$ and Viswanadha Srirama Rajasekhar Pullabhotla ${ }^{2, *(1)}$ \\ 1 Department of Biochemistry and Microbiology, University of Zululand, Private Bag X1001, \\ KwaDlangezwa 3886, South Africa; nathidlamini03@gmail.com (N.G.D.); Bassona@unizulu.ac.za (A.K.B.); \\ ShanduJ@unizulu.ac.za (S.J.S.E.) \\ 2 Department of Chemistry, University of Zululand, Private Bag X1001, KwaDlangezwa 3886, South Africa \\ * Correspondence: PullabhotlaV@unizulu.ac.za; Tel.: +27-35-902 6155
}

Received: 27 November 2019; Accepted: 8 January 2020; Published: 7 July 2020

check for updates

\begin{abstract}
Green synthesis of core-shell nanoparticles is gaining importance nowadays as it is viewed as being environmental friendly and cost effective. The present study aimed to synthesize iron@copper core-shell nanoparticles using a polysaccharide-based bioflocculant from Alcalegenis faecalis and to evaluate its efficiency in dye removal and river water and domestic wastewater treatment. The synthesized samples were characterized by Fourier-transform infrared spectroscopy, $\mathrm{X}$-ray diffraction, scanning electron microscopy, thermogravimetric analysis, transmission electron microscopy, and UV-Vis spectroscopy analysis. To optimize the best concentration for core-shell formation, different ratios of iron to copper were prepared. Sample 1 (S1) contained 1:3 iron to copper (Fe 25\%-Cu 75\%), sample 2 (S2) contained 1:1 iron to copper (Fe 50\%-Cu 50\%), and the third sample (S3) contained 3:1 iron to copper (Fe 75\%-Cu 25\%). The flocculation activity (FA) was above $98 \%$ at $0.2 \mathrm{mg} / \mathrm{mL}$ for all the samples and the samples flocculated well under acidic, alkaline, and neutral $\mathrm{pH}$ conditions. Sample 3 was shown to be thermostable, with flocculation activity above $90 \%$, and samples 2 and 1 were also thermostable, but the flocculation decreased to 87 at $100{ }^{\circ} \mathrm{C}$. All three samples revealed some remarkable properties for staining dye removal as the removal efficiency was above $89 \%$ for all dyes tested. The synthesized core-shell nanoparticles could remove nutrients such as total nitrogen and phosphate in both domestic wastewater and Mzingazi river water. Furthermore, high removal efficiency for chemical oxygen demand (COD) and biological oxygen demand (BOD) was also observed.
\end{abstract}

Keywords: core-shell nanoparticles; removal efficiency; optimization; synthesis

\section{Introduction}

Drinking water scarcity, i.e., water free of pathogens and toxic chemical substances, is a worldwide problem due to population growth, extended droughts, competing demands from different users, and more health-based regulations. However, the conditions are very severe in developing countries [1]. Chemical flocculants are widely used nowadays owing to their low-cost, effective flocculation performance. However, their application has been found to cause environmental and health hazards such as Alzheimer's disease [2]. Use of bioflocculants has gained interest in recent years due to the biodegradability properties bioflocculants possess and their negligible environmental hazards. Nonetheless, higher production costs and low flocculation yields are limitations to the industrial application of bioflocculants [3]. Consequently, in recent years research has mainly focused on the synthesis of nanoparticles from bioflocculants and their application in industrial effluents and 
wastewater treatment. Alternatively, composite flocculants serve as a way to reduce cost as they can flocculate well even at low dosages and reduce the risk of adverse effects that come with synthetic flocculants since their dosage is reduced to the smallest possible [3].

Textile industries discharge tons of effluents to the environment which contain pollutants and dyes that are carcinogenic in nature and non-degradable [4]. Furthermore, most of the paper and textile industries use dyes and discharge the effluents to water resources. Technologies such as hydrogen peroxide and UV radiation are not effective in relation to these dyes as they are chemically stable. Recent findings suggest that nanomaterials can be successfully used in dye degradation, making nanoparticles to be more profitable compared to chemical and physical methods [4]. Furthermore, copper nanoparticles have been found to be effective in wastewater treatment. They have been found to be able to remove up to $88 \%$ and $90 \%$ of chemical oxygen demand (COD) and biological oxygen demand (BOD), respectively, in mine wastewater, domestic wastewater, and river water [5]. Similarly, iron oxide nanoparticles have been widely applied in the removal of chemical pollutants from water in a separation process known as adsorption [6].

In the present study, iron@copper core-shell nanoparticles are synthesized using a bioflocculant from marine species Alcalegenis faecalis. The bioflocculant which is used for synthesis is composed of mainly carbohydrates. Copper sulphate $\left(\mathrm{CuSO}_{4}\right)$ and iron chloride $\left(\mathrm{FeCl}_{3}\right)$ are used as the precursors for the iron@copper nanoparticles. Different ratios of iron to copper (1:3, 1:1, and 3:1) are prepared to optimize the most effective combination. Various parameters such as dosage, $\mathrm{pH}$, temperature, and cations are varied to optimize the effectiveness of the synthesized iron@copper core-shell nanoparticles in flocculation efficiency and are tested against kaolin clay as a standard test material.

\section{Results}

\subsection{X-Ray Diffraction Studies of S1, S2, and S3}

X-ray diffraction patterns of samples S1, S2, and S3 are shown in Figure 1. Strong and characteristic crystalline peaks are observed between $30^{\circ}$ and $50^{\circ} 2 \theta$.

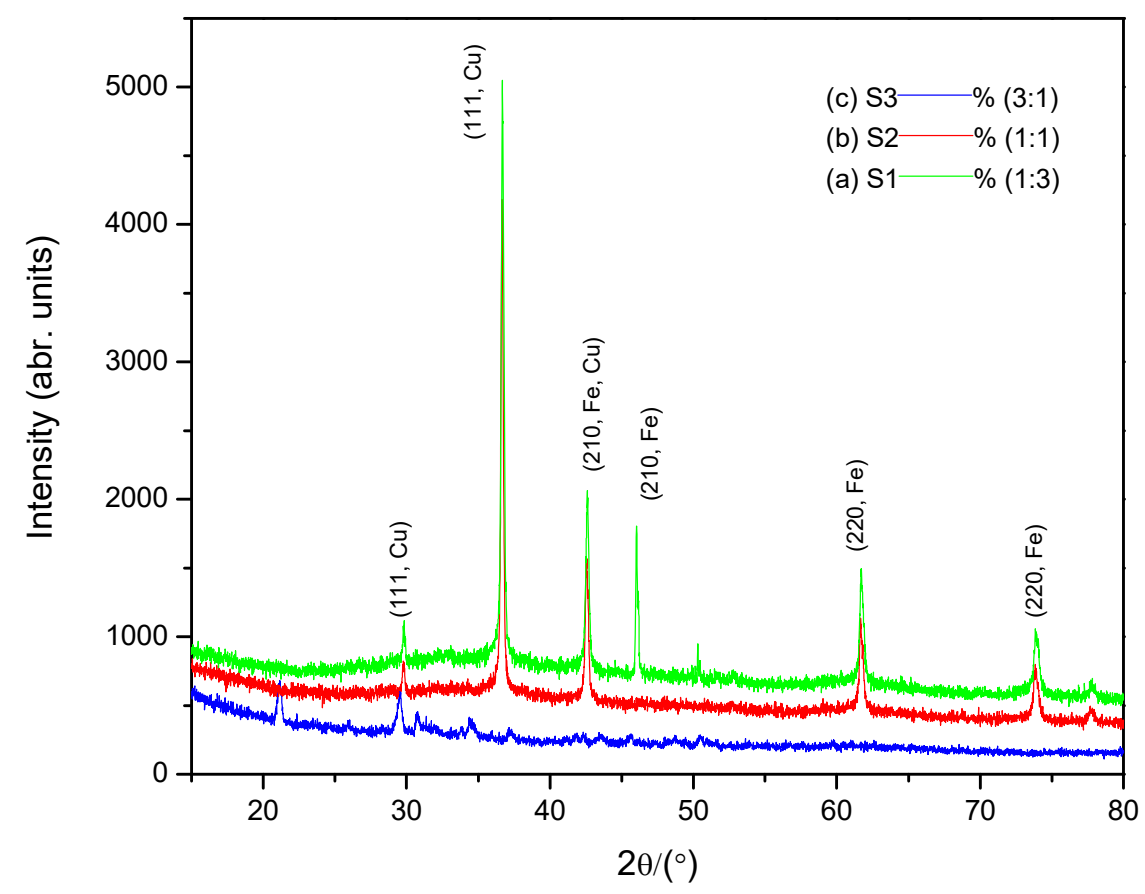

Figure 1. X-ray diffractograms of samples (a) S1, (b) S2, and (c) S3. 


\subsection{FT-IR Spectra of S1, S2, and S3 Nanoparticles}

Figure 2 shows the functional groups that are present in S1, S2, and S3. Figure 2 indicates the presence of a hydroxyl $(-\mathrm{OH})$ group at $3250 \mathrm{~cm}^{-1}$ and an amine $\left(-\mathrm{NH}_{2}\right)$ group at $1750 \mathrm{~cm}^{-1}$ in the samples. The weak band at $2244 \mathrm{~cm}^{-1}$ for all samples can be attributed to the presence of aliphatic bonds.

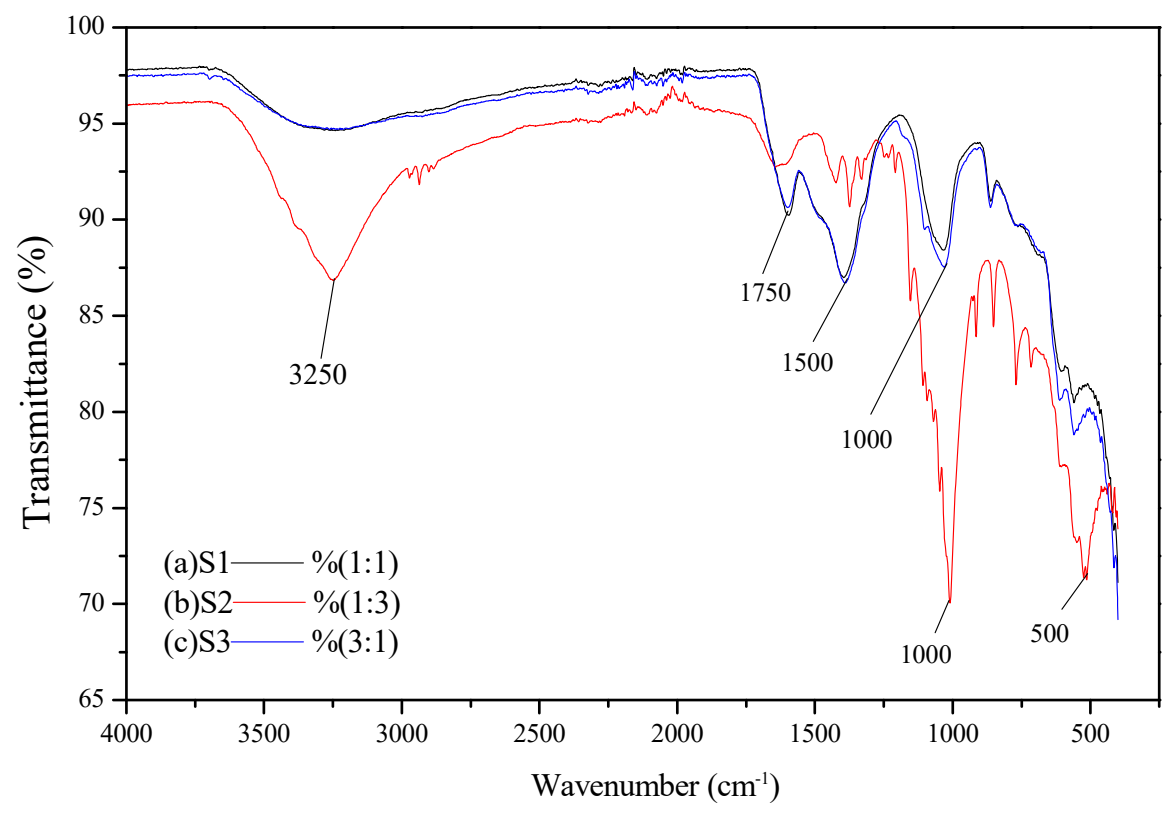

Figure 2. FT-IR spectra of samples (a) S1, (b) S2, and (c) S3.

\subsection{Morphological Studies of S1, S2, and S3 Using SEM}

Figure 3 shows SEM images of samples S1, S2, and S3. Granular-like morphology is evident from Figure 3 for all three samples.

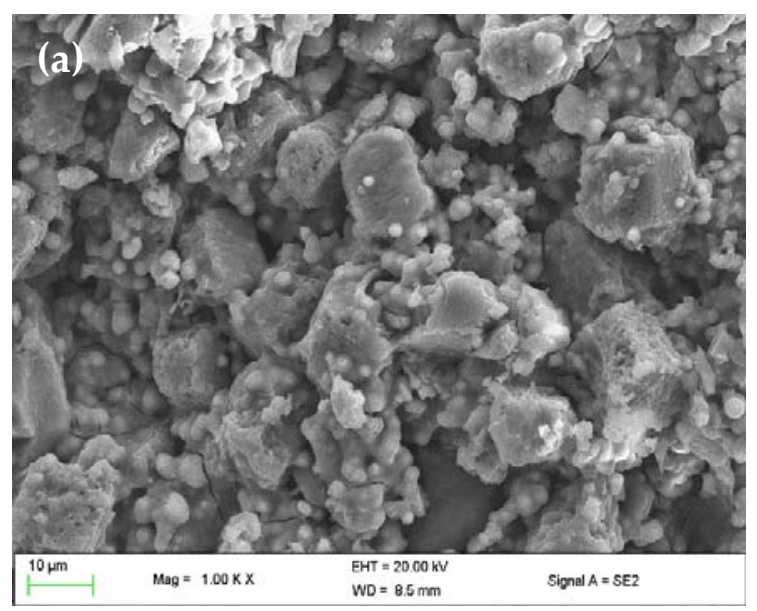

Figure 3. Cont. 

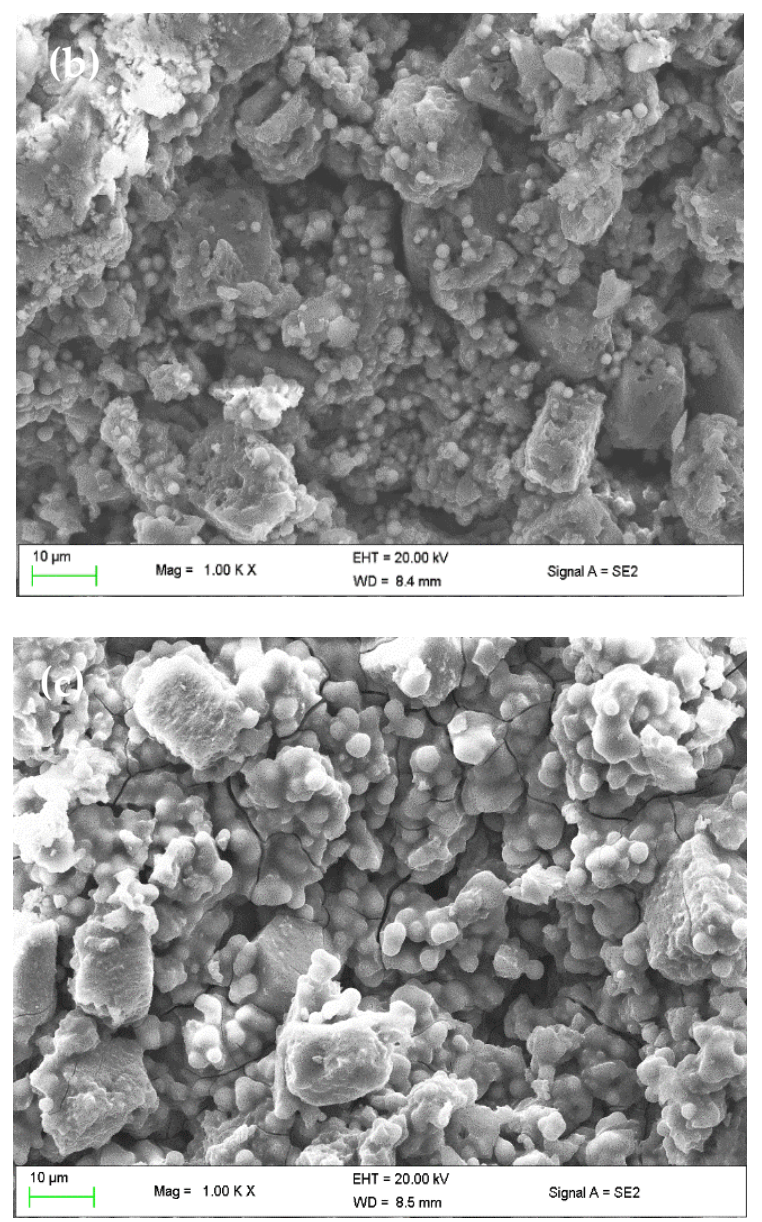

Figure 3. SEM images of samples (a) S1, (b) S2, and (c) S3.

\subsection{Elemental Analysis of S1, S2, and S3 Using SEM-Energy-Dispersive X-Ray Analysis (EDX)}

Table 1 represents SEM-EDX results of samples S1, S2, and S3. The wt.\% of the elements C, O, Na, $\mathrm{Mg}, \mathrm{P}, \mathrm{S}, \mathrm{Cl}, \mathrm{Ca}, \mathrm{Fe}$ and $\mathrm{Cu}$ present in the samples $\mathrm{S} 1, \mathrm{~S} 2$, and S3.

Table 1. Energy-dispersive X-ray analysis (EDX) of samples (a) S1, (b) S2, and (c) S3.

\begin{tabular}{cccc}
\hline \multirow{2}{*}{ Elements } & \multicolumn{3}{c}{ Sample } \\
\cline { 2 - 4 } & S1 (wt.\%) & S2 (wt.\%) & S3 (wt.\%) \\
\hline $\mathbf{C}$ & 13.74 & 19.07 & 16.27 \\
\hline $\mathbf{O}$ & 53.97 & 55.09 & 54.14 \\
\hline $\mathbf{N a}$ & 8.53 & 7.01 & 8.22 \\
\hline $\mathbf{M g}$ & 14.10 & 12.27 & 12.42 \\
\hline $\mathbf{P}$ & 1.30 & 0.63 & 0.94 \\
\hline $\mathbf{S}$ & 0.39 & - & 0.38 \\
\hline $\mathbf{C l}$ & 0.17 & 0.20 & 0.08 \\
\hline $\mathbf{C a}$ & 1.34 & 0.70 & 0.76 \\
\hline Fe & 1.65 & 1.19 & 0.83 \\
\hline $\mathbf{C u}$ & 4.82 & 3.83 & 5.96 \\
\hline Total & 100.00 & 100.00 & 100.00 \\
\hline
\end{tabular}




\subsection{The Effect of Various Metal Ratios in the Flocculation Process}

Figure 4 shows the effect of various samples with different proportions of iron to copper on flocculation activity. The first sample (S1) contained 1:3 iron to copper ( $\mathrm{Fe} 25 \%-\mathrm{Cu} 75 \%$ ), sample 2 (S2) contained 1:1 iron to copper (Fe 50\%-Cu 50\%), and the third sample (S3) contained 3:1 iron to copper (Fe 75\%-Cu 25\%). All the samples (S1, S2, and S3) were found to flocculate best at the lowest concentration of $0.2 \mathrm{mg} / \mathrm{mL}$.

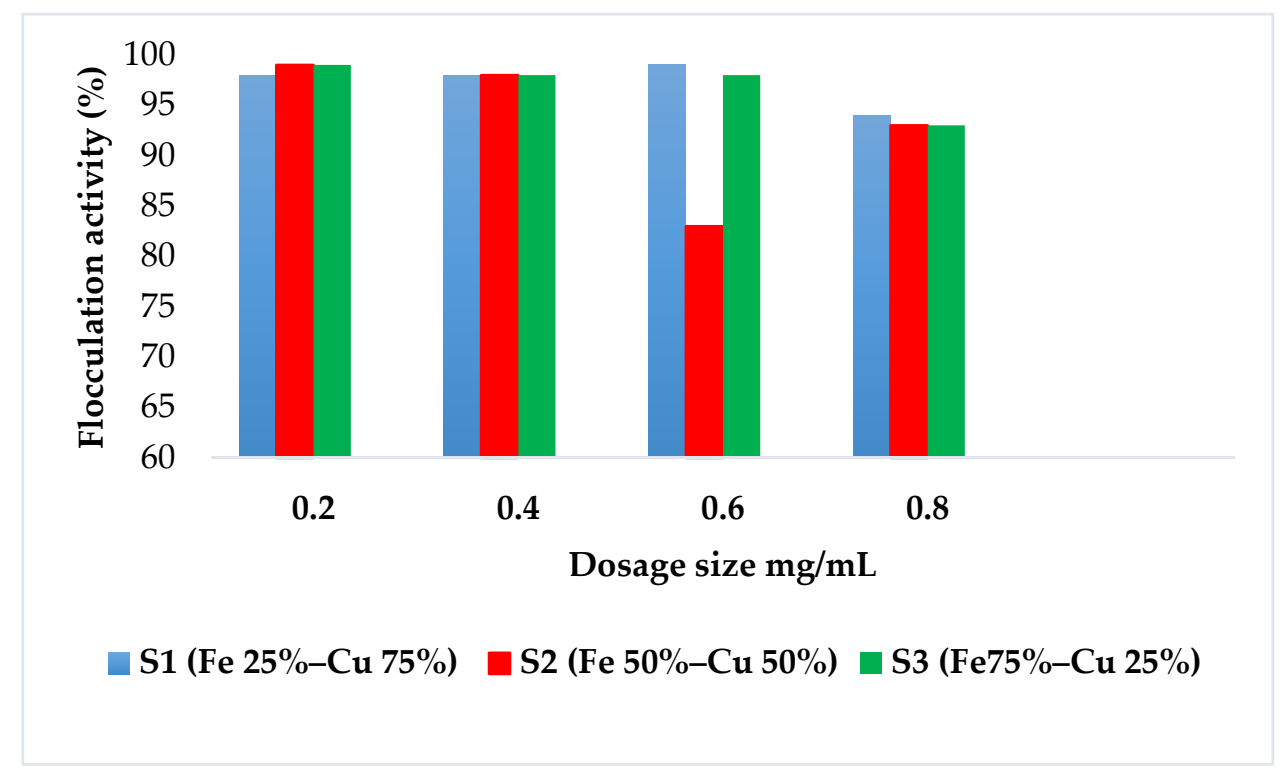

Figure 4. Dosage effect on flocculation activity of nanoparticle samples S1, S2, and S3.

\subsection{Effect of $\mathrm{pH}$ on the Flocculation Process}

Figure 5 shows the effect of $\mathrm{pH}$ on the flocculation activity of different samples with different proportions of iron to copper (Fe 25\%-Cu $75 \%$ for S1, Fe 50\%-Cu 50\% for S2, and $\mathrm{Fe} 75 \%-\mathrm{Cu} 25 \%$ for S3). All samples indicated that they are able to flocculate under extremely acidic and extremely basic $\mathrm{pH}$ with flocculation activity above $95 \%$.

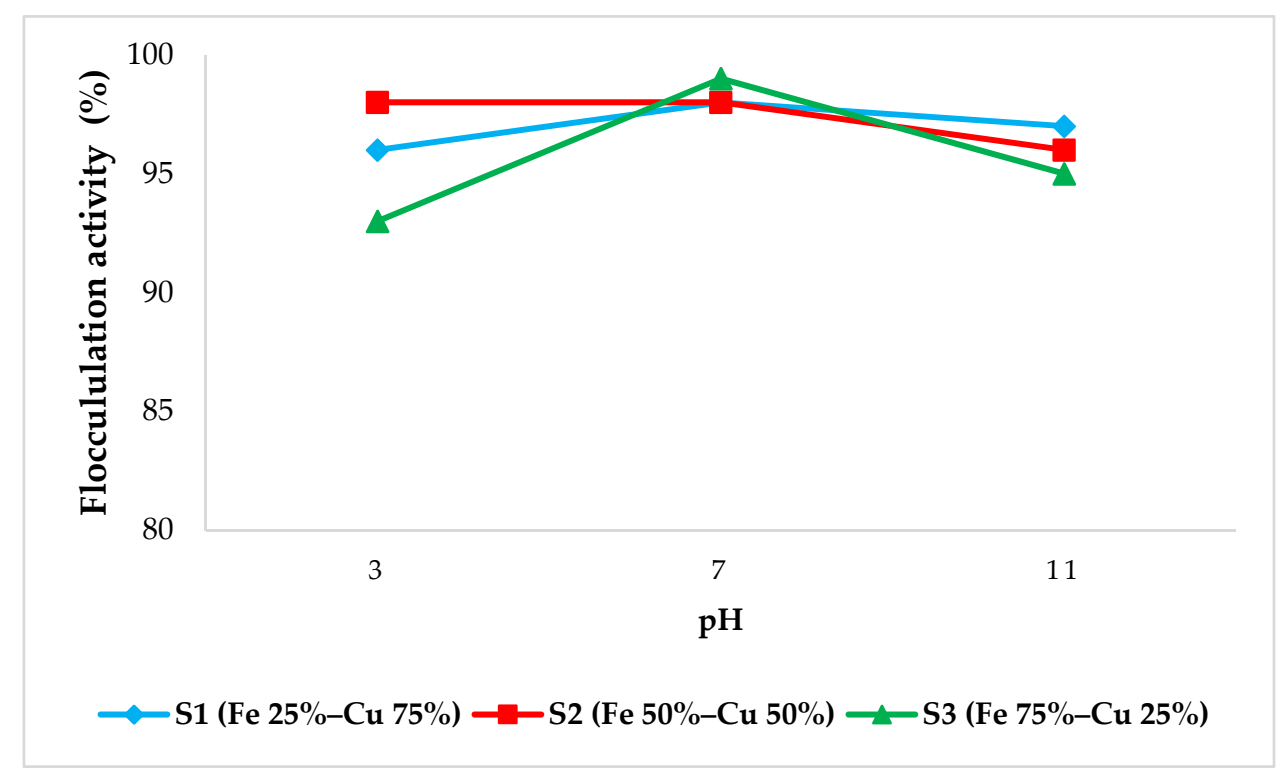

Figure 5. pH effect on the flocculation activity of nanoparticle samples S1, S2, and S3. 


\subsection{The Effect of the Presence of Different Metal Ions in the Flocculation Process}

Table 2 represents the effect of cations on samples S1, S2, and S3 with regard to flocculation activity. All the samples were found to be able to flocculate effectively in the absence of cations, with flocculation activity found to be above $95 \%$.

Table 2. Effect of cations on flocculation activity of nanoparticles.

\begin{tabular}{ccccc}
\hline \multirow{2}{*}{ Type of Flocculant Cation FA (\%) \pm SD } \\
\cline { 2 - 5 } & Control & $\mathbf{N a}^{+}$ & $\mathbf{C a}^{\mathbf{2 +}}$ & $\mathbf{F e}^{\mathbf{3 +}}$ \\
\hline S3 & $95 \pm 0.031^{\mathrm{a}}$ & $97 \pm 0.012^{\mathrm{a}}$ & $99 \pm 0.025^{\mathrm{a}}$ & $97 \pm 0.037^{\mathrm{a}}$ \\
\hline S2 & $96 \pm 0.003^{\mathrm{a}}$ & $95 \pm 0.063^{\mathrm{a}}$ & $98 \pm 0.007^{\mathrm{a}}$ & $87 \pm 0.023^{\mathrm{b}}$ \\
\hline S1 & $96 \pm 0.039^{\mathrm{a}}$ & $95 \pm 0.051^{\mathrm{a}}$ & $98 \pm 0.012^{\mathrm{a}}$ & $97 \pm 0.014^{\mathrm{a}}$ \\
\hline
\end{tabular}

Values represent mean \pm deviation of replicate readings. Percentage flocculation activities with different letters $(a$ and $b)$ are significantly $(p<0.05)$ different. Legend: FA, flocculation activity.

\subsection{Thermostability Test for Samples S1, S2, and S3}

Figure 6 represents the effect of temperature on flocculation activity. All the samples were shown to be thermostable, with flocculation above $80 \%$ at $100{ }^{\circ} \mathrm{C}$. Sample 3 was the most stable with a flocculation activity of $93 \%$.

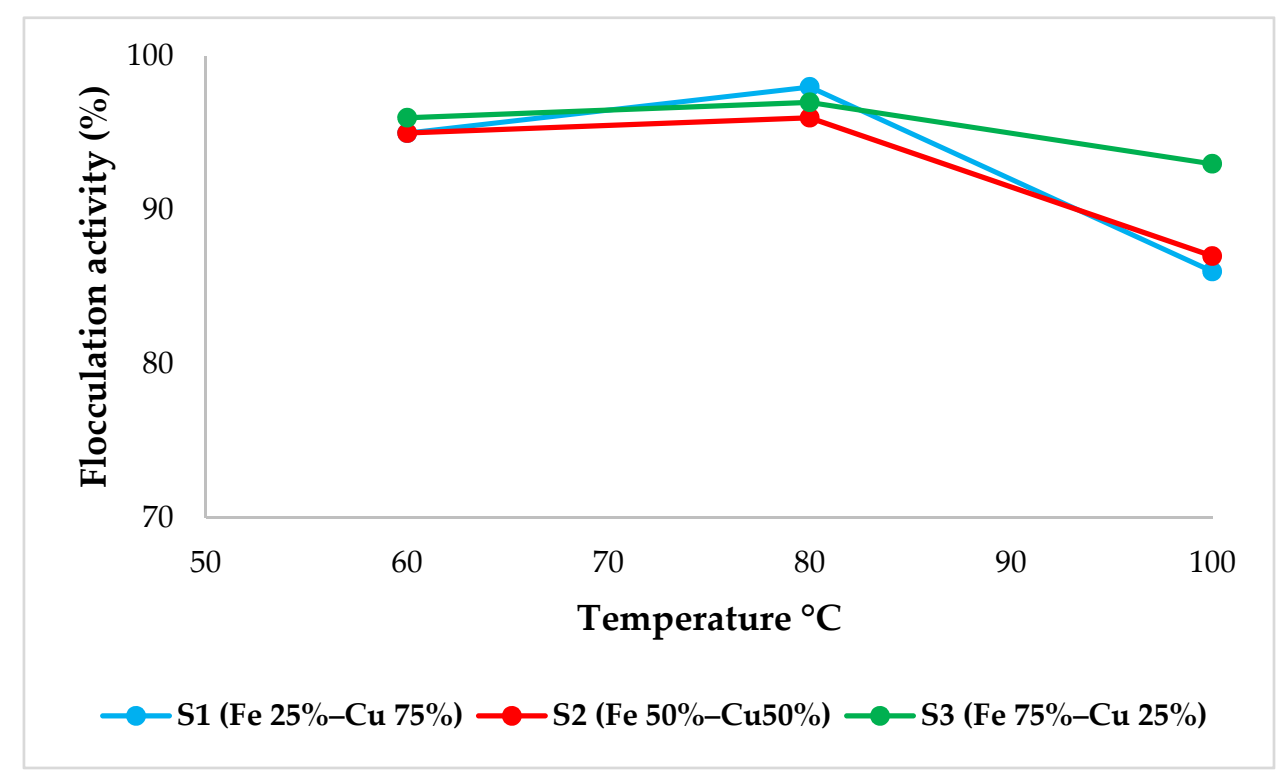

Figure 6. Effect of temperature on flocculation process of samples S1, S2, and S3.

\subsection{The Removal Efficiency of Staining Dyes by Nanoparticle Samples S1, S2, and S3}

Figure 7 shows the removal efficiency of staining dyes by nanoparticle samples S1, S2, and S3. All the samples showed an excellent ability to remove the staining dyes. Sample 3 had an efficiency of above $90 \%$ for the four dyes (safranin, methylene blue, methylene orange, and malachite green) which were examined. 


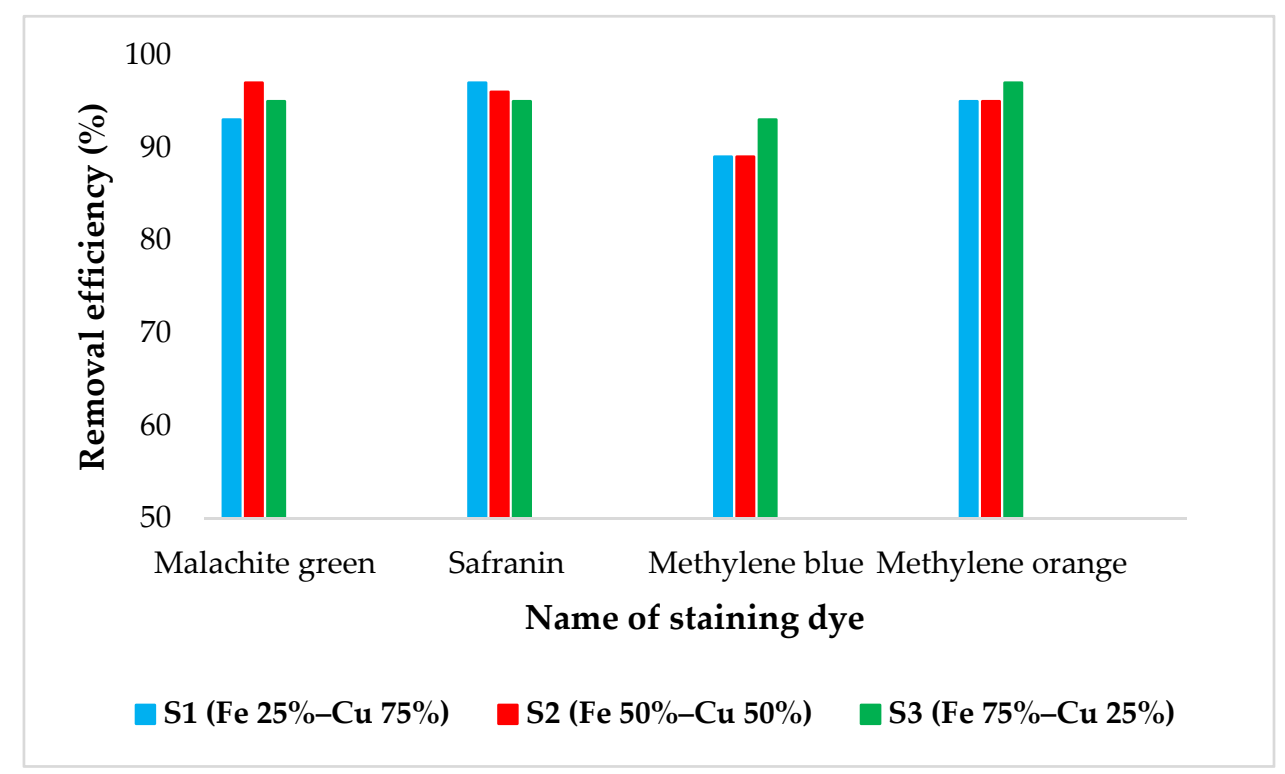

Figure 7. Removal efficiency of dyes by nanoparticle samples S1, S2, and S3.

\subsection{Removal Efficiency of Nutrients in Wastewater by Nanoparticle Samples S1, S2, and S3}

Table 3 shows the removal of COD, BOD, phosphate and total nitrogen in Vulindlela wastewater and Mzingazi River water by nanoparticle samples S1, S2, and S3. S3 was observed to be the most effective in removing both phosphate and total nitrogen, with a removal efficiency of above $97 \%$.

Table 3. Removal of pollutants in Vulindlela wastewater and Mzingazi River by nanoparticle samples S1, S2, and S3. Legend: COD, chemical oxygen demand; BOD, biological oxygen demand.

\begin{tabular}{|c|c|c|c|c|c|c|c|c|c|c|c|c|c|}
\hline \multirow[b]{3}{*}{$\begin{array}{l}\text { Type of } \\
\text { Flocculant }\end{array}$} & \multirow[b]{3}{*}{$\begin{array}{c}\text { Type of } \\
\text { Wastewater }\end{array}$} & \multicolumn{8}{|c|}{ Type of Pollutants } & \multicolumn{4}{|c|}{ Removal Efficiency (\%) } \\
\hline & & \multicolumn{4}{|c|}{ Water Quality Before Treatment } & \multicolumn{4}{|c|}{ Water Quality After Treatment } & \multicolumn{2}{|c|}{ COD BOD } & \multirow{2}{*}{$\begin{array}{l}\mathbf{P} \\
-\end{array}$} & \multirow{2}{*}{$\begin{array}{l}\mathbf{N} \\
-\end{array}$} \\
\hline & & $\begin{array}{l}\text { COD } \\
\mathrm{mg} / \mathrm{mL}\end{array}$ & $\begin{array}{l}\text { BOD } \\
\mathrm{mg} / \mathrm{mL}\end{array}$ & $\begin{array}{c}P \\
\mathrm{mg} / \mathrm{mL}\end{array}$ & $\begin{array}{l}\text { Total } \\
\text { nitrogen } \\
\mathrm{mg} / \mathrm{mL}\end{array}$ & $\begin{array}{l}\text { COD } \\
\mathrm{mg} / \mathrm{mL}\end{array}$ & $\begin{array}{l}\text { BOD } \\
\mathrm{mg} / \mathrm{mL}\end{array}$ & $\underset{\mathrm{mg} / \mathrm{mL}}{P}$ & $\begin{array}{l}\text { Total } \\
\mathrm{mg} / \mathrm{mL}\end{array}$ & - & - & & \\
\hline \multirow[b]{2}{*}{ S1 } & Domestic & 2.313 & 123 & 3.38 & 0.223 & 1.151 & 17 & 2.55 & 0.017 & 50 & 86 & 37 & 88 \\
\hline & $\begin{array}{l}\text { Mzingazi } \\
\text { river }\end{array}$ & 3.300 & 146 & 85.7 & 0.127 & 1.074 & 15 & 0.120 & 0.020 & 67 & 87 & 99 & 84 \\
\hline \multirow[b]{2}{*}{ S2 } & Domestic & 2.313 & 123 & 3.38 & 0.223 & 1.152 & 13 & 0.69 & 0.124 & 50 & 89 & 80 & 44 \\
\hline & $\begin{array}{l}\text { Mzingazi } \\
\text { river }\end{array}$ & 3.300 & 146 & 85.7 & 0.127 & 1.900 & 21 & 0.121 & 0.025 & 42 & 86 & 99 & 80 \\
\hline \multirow[b]{2}{*}{ S3 } & Domestic & 2.313 & 123 & 3.38 & 0.223 & 0.464 & 19 & 0.09 & 0.014 & 85 & 91 & 97 & 98 \\
\hline & $\begin{array}{l}\text { Mzingazi } \\
\text { river }\end{array}$ & 3.300 & 146 & 85.7 & 0.127 & 0.793 & 31 & 0.109 & 0.023 & 79 & 72 & 99 & 82 \\
\hline
\end{tabular}

\section{Discussion}

In Figure 1 the strong peaks can be observed at $2 \theta \sim 35^{\circ}, 40^{\circ}$, and $65^{\circ}$ for S1. Contrary to this, it can be noted that the strongest peaks were at $2 \theta \sim 35^{\circ}, 45^{\circ}, 65^{\circ}$, and $77^{\circ}$ for S2. In S3, the strongest peaks can be is observed at $2 \theta \sim 22^{\circ}$ and $30^{\circ}$. However, these peaks are not as strong as those seen in S2. Strong peaks normally represent crystallinity and smaller particle size. It can be observed that the S3 diffractogram behaves differently from those of the other two samples. This might be attributed to the synergistic effect that results from the changed sample composition.

It can be deduced that when the proportion of iron to copper is 1:3 the size of the as-synthesized Fe@Cu core-shell nanoparticles become smaller. Different functional groups serve as the binding sites for flocculants during the flocculation process [7]. Higher flocculation ability of the samples can be attributed to the presence of different functional groups as observed in Figure 2. Different functional 
groups were revealed by FT-IR spectroscopy analysis. Hydroxyl (-OH) and amine $\left(-\mathrm{NH}_{2}\right)$ groups were observed in the same plane for samples S1 and S2, respectively. The amine group could have originated from the bioflocculant that was used [7]. The peaks at $1700-1500 \mathrm{~cm}^{-1}$ signify the presence of a $\mathrm{C}=\mathrm{O}$ amide group and the deep peak in the $1200 \mathrm{~cm}^{-1}$ region is typical of $\mathrm{C}-\mathrm{OH}$ stretching. C-O-C stretching can be observed at $1250-1050 \mathrm{~cm}^{-1}$ as depicted in Figure 2. The strong peak in sample S2 at $500 \mathrm{~cm}^{-1}$ is typical of $\mathrm{C}-\mathrm{Cl}$; this was also confirmed by the presence of $\mathrm{Cl}$ in the SEM-EDX analysis.

The morphology of S1, S2, and S3 as observed under SEM are shown in Figure 3. A change in morphology was observed and the proportion of iron to copper also changed. S1 had a rough amorphous-like structure with granules and in S2 the structure was similar to that of S1 but with much smaller granules. Contrary to this, S3 had a smooth amorphous structure with big granules, which signifies a structural transition as the ratio of iron to copper was varied. SEM-EDX analysis of samples S1, S2, and S3 showed different elements that are present. From Table 1 (sample S1) elements such as $\mathrm{O}, \mathrm{Mg}$, and $\mathrm{Na}$ can be seen to be abundant in huge percentages, with oxygen having $53.97 \mathrm{wt} . \%$, magnesium $14.10 \mathrm{wt} . \%$, and $\mathrm{Na} 8.53 \mathrm{wt} . \%$. Cu was the fourth highest element, having over $4 \mathrm{wt} . \%$, while Fe had $1.65 \mathrm{wt} . \%$. The first three elements, which are present in abundance, could owe their abundance to the results of the culture medium which was used to grow the microorganism for bioflocculant production. From Table 1 (sample S2), elements such as $\mathrm{O}, \mathrm{Mg}, \mathrm{Na}, \mathrm{Cu}$, and Fe can be seen to be the most dominant in sample S2, with oxygen, magnesium, and sodium making up $74.37 \mathrm{wt} . \%$ combined. This is due to the fact that these elements form part of the structure of the biomolecule (bioflocculant) which was used during synthesis, and, also, the fact that the medium which was used for bioflocculant production consist of these elements. Lastly, in sample S3 (Table 1) a significant increase in $\mathrm{Cu}$ is observed in comparison to the other two samples. However, $\mathrm{O}, \mathrm{Mg}$, and $\mathrm{Na}$ are still present in high proportions, just like in the rest of the samples.

UV-Vis spectroscopy and TEM and TGA analysis were also performed on these materials. UV-Vis spectra revealed plasmon resonance (SPR) spectra with an absorbance range of 295-500 nm; the peak maxima for the synthesized particles was observed at around $300 \mathrm{~nm}$ (Figure S1). TEM images show that the higher aggregation of particles could be due to the surfactant (bioflocculant) matrix (Figure S2). The inset TEM image also indicates the extent of aggregation (Figure S2). Selected area electron diffraction on the iron@copper core-shell nanoparticles failed to show any discernible electron diffraction, indicating that the iron@copper core-shell nanoparticles are amorphous. In the TGA analysis, all three samples seemed to be shown to be thermostable, as they retained over $50 \%$ of their weight at over $800{ }^{\circ} \mathrm{C}$ (Figure S3).

Sworska et al. [8] have posited that there are various flocculation mechanisms but that flocculation by bridging is the most important. Adsorption of flocculant segments onto the surface of more than one particle is described as bridging. In sample S1 it was found that flocculation activity remained almost constant, being $98 \%$ for the range $0.2-0.6 \mathrm{mg} / \mathrm{mL}$, suggesting that the optimum dosage used for bridging to occur should be below $0.8 \mathrm{mg} / \mathrm{mL}$. The best flocculation is observed at flocculant dosages corresponding to particle coverage that is significantly less than complete [8]. In S2, the flocculation activity fluctuated for the range $0.4-0.8 \mathrm{mg} / \mathrm{mL}$, as observed in Figure 4, which could be due to the synergetic effect between the iron and copper metal ions. A similar trend as in $\mathrm{S} 1$ was also witnessed in S3: the flocculation activity remained almost the same for the range $0.2-0.6 \mathrm{mg} / \mathrm{mL}$, and it started to decrease at $0.8 \mathrm{mg} / \mathrm{mL}$. The effect of $\mathrm{pH}$ on flocculation activity was evaluated in accordance with a description by Zaki et al. [9] where $1.0 \mathrm{M} \mathrm{HCl}$ and $1.0 \mathrm{M} \mathrm{NaOH}$ were used for $\mathrm{pH}$ adjustment whenever necessary. All the samples could flocculate best under all $\mathrm{pH}$ conditions (acidic, neutral, and alkaline) with above $90 \%$ flocculation. As presented in Figure 5, the optimal flocculation activity was achieved at neutral $\mathrm{pH}$; however, the flocculation activity was still above $90 \%$ for both under acidic and alkaline conditions, suggesting that the nanoparticles are $\mathrm{pH}$ stable. The absorption of $\mathrm{H}^{+}$ions tends to weaken the nanoparticle-kaolin complex formation at acidic and alkaline $\mathrm{pH}$ [9]. This remarkable property of iron@copper core-shell nanoparticles to withstand acidic and alkaline $\mathrm{pH}$ could be contributed to by the ability of core-shell nanomaterials to withstand harsh conditions 
which is brought about by the relationship between the core and the shell [10]. These nanoparticles are of commercial value, as they can flocculate acidic and alkaline water. Cations enhance flocculation activity by balancing the negatively charged kaolin suspension and that of the functional group of the flocculants [11]. Equally, monovalent, divalent, and trivalent cations could enhance the flocculation process. However, in this case, the synthesized nanoparticles proved to be independent of cations, as the flocculation was above $95 \%$ when there were no cations added. The limitations of bioflocculants are their high production cost and low flocculation efficiency as compared to their counterpart synthetic flocculants; some of the bioflocculants require cations to work effectively. These findings suggest that the synthesized iron@copper core-shell nanoparticles could be cost-effective as their flocculation activity was found to be above $95 \%$ in the absence of cations. As depicted in Table 2 above, both S1 and S2 flocculate best with $\mathrm{Fe}^{3+}$; however, the results show that the difference between the control and $\mathrm{Fe}^{3+}$ is not significant. Sample 3 showed a decreased flocculation activity when $\mathrm{Fe}^{3+}$ was added, suggesting that the sample works better in the absence of cations. The effectiveness of samples S1, S2, and S3 when heated at high temperatures was examined for the temperature range $60-100{ }^{\circ} \mathrm{C}$. The samples were subjected to high temperatures in a water bath for $30 \mathrm{~min}$ before the flocculation activity was measured. The flocculation activity of all the samples remained almost the same for the range $60-80{ }^{\circ} \mathrm{C}$ and started to decrease when the temperature was increased to $100^{\circ} \mathrm{C}$. Sample 3 was found to be the most stable of the three samples, with the flocculation activity remaining above $90 \%$ even when the sample was subjected to the higher temperature of $100^{\circ} \mathrm{C}$. Contrarily, samples S1 and S2 revealed a slight decrease in flocculation activity when they were exposed to the high temperature of $100^{\circ} \mathrm{C}$, with flocculation activity decreasing from 97 to $87 \%$. Giri et al. [12] have reported a thermostable bioflocculant which maintains up to $89 \%$ flocculation activity at the high temperature of $100{ }^{\circ} \mathrm{C}$. Most bioflocculants which are composed mainly of carbohydrates and of few proteins are able to withstand high temperatures [12]. The bioflocculant which was used for synthesis was composed mainly of carbohydrates, which could be the reason for the high thermostability of the nanoparticles studied here, and literature suggests that such bioflocculants are thermally stable [9]. Moreover, core-shell nanoparticles are said to be able to withstand extreme conditions due to the synergistic effect between the core and the shell [13].

Treatment of some discharged effluents from some industries is still a serious issue, as some of these discharges contain colorful dyes [14]. The pharmaceutical, leather, paper, textile, sugar, cosmetic, food, and printing industries are the most common discharging industries. These colorful dyes have serious impacts on ecosystems, with the dyes preventing light penetration within rivers and at the bottom of lakes and ponds, hindering photosynthesis in plants. Moreover, they may also lead to anaerobic conditions that can be fatal to aquatic life. As presented in Figure 7 above, the samples were prepared by mixing $4 \mathrm{~g}$ of dye in 1 liter of distilled water, and $100 \mathrm{~mL}$ of the dye solution was mixed with $2 \mathrm{~mL}$ of $0.2 \mathrm{mg} / \mathrm{mL}$ of nanoparticle solution (S1, S2, and S3). The mixture was agitated for a minute and transferred to a graduated measuring cylinder, and then left to stand for $5 \mathrm{~min}$ before it was analyzed using a spectrophotometer. The nanoparticles were very effective in relation to staining dye removal and the efficiency was above $89 \%$ for all for just a 5 min contact time. Vulindlela is a domestic wastewater treatment plant and is located within the locality of the University of Zululand. The plant treats water before it is discharged to the surrounding streams. It is of the utmost importance to treat water before it is discharged as some of the surrounding community uses the streams' water for domestic crop farming purposes. As shown in Table 3, sample S3 was the most effective in removing both phosphate and total nitrogen while samples S1 and S2 could only remove total nitrogen and phosphate, respectively. For the removal of COD in the wastewater, both samples S1 and S2 were not so effective, with merely a 50\% removal efficiency observed. Contrary to this, sample S3 was the most effective, with $80 \%$ COD removal. Mzingazi River is geographically located around the city of Richards Bay, which has a high activity of industrialization and sugarcane farming. This accounts for the high phosphate content in the water, as some phosphate is washed by rain from farming fertilizers and industries into the river. Excess accumulation in water has an adverse impact on aquatic life; 
it may cause "brown blood diseases" in fish or it may result to eutrophication [15]. Table 3 shows results for the samples that were able to remove up to $99 \%$ of phosphate when it was left to stand for one week; over $80 \%$ of total nitrogen was removed when the samples were prepared following the manufacturer's instructions on the test kit. Hence, it can be deduced that for nanoparticles to give an optimum removal efficiency for phosphate, the samples should be allowed a longer contact time. With regard to COD removal, samples S1 and S3 were able to remove $67 \%$ and $79 \%$, respectively, while sample S2 could only remove $42 \%$ of COD from the water. In Table 3, all the samples, i.e., S1, S2, and S3, can be seen to have remarkable properties with regard to BOD removal for both domestic wastewater and river water. The removal efficiency was over $80 \%$ for all tested water, except for S3 in Mzingazi river water, where it was just 79\%.

\section{Materials and Methods}

\subsection{Synthesis of Iron@Copper Core-Shell Nanoparticles}

The synthesis of core-shell nanoparticles was achieved using the description by Yu et al. [16], where $10 \mathrm{~mL}$ of $0.02 \mathrm{M} \mathrm{FeCl}_{3}$ aqueous solution was prepared in a flask, after which $0.5 \mathrm{~g}$ of bioflocculant was added. A $10 \mathrm{~mL}$ aliquot of $5.0 \mathrm{M} \mathrm{NaOH}$ was added to the solution of $\mathrm{FeCl}_{3}$ at room temperature. This mixture was added into a $10 \mathrm{~mL}$ solution of glucose $(1.0 \mathrm{M})$. A color change indicated the formation of iron nanoparticles. To obtain different ratios of iron to copper, different volumes were prepared. The first ratio of 1:3 was prepared by mixing $25 \mathrm{~mL}(0.003 \mathrm{M}) \mathrm{FeCl}_{3}$ with $75 \mathrm{~mL}(0.003 \mathrm{M})$ of $\mathrm{CuCl}_{2}$ and the 1:1 ratio was achieved by mixing $50 \mathrm{~mL}$ of each sample as indicated; consequently, the final 3:1 ratio was obtained by mixing $75 \mathrm{~mL}(0.003 \mathrm{M})$ of $\mathrm{FeCl}_{3}$ and $25 \mathrm{~mL}(0.003 \mathrm{M})$ of $\mathrm{CuCl}_{2}$. All different ratios were prepared and added into $0.5 \mathrm{~g}$ of purified bioflocculant. The reaction was allowed to continue for $20 \mathrm{~min}$ and the resulting precipitate was collected through centrifugation at $15000 \mathrm{rmp}, 4{ }^{\circ} \mathrm{C}$, for $30 \mathrm{~min}$ [16].

\subsection{Test for Flocculation Activity of S1, S2, and S3}

Flocculation activity was evaluated using a method developed by Kurane et al. [17] with a slight modification, where $4 \mathrm{~g}$ of kaolin clay was dissolved in a liter of distilled water. One hundred milliliters of the prepared kaolin solution was mixed with $2 \mathrm{~mL}$ of nanoparticle solution at a concentration of $2 \mathrm{mg} / \mathrm{mL}$ and $3 \mathrm{~mL}$ of $\mathrm{CaCl}_{2}(1 \mathrm{~g} / \mathrm{L})$ solution was also added, after which the mixture was shaken for a minute and transferred to a $100 \mathrm{~mL}$ graduated measuring cylinder. To observe the flocculation ability of the synthesized core-shell nanoparticles the mixture was left to stand for $5 \mathrm{~min}$ at room temperature and only the upper part was employed for analysis using a Pharo 100 Spectrophotometer ${ }^{\circledR}$ (Capital Lab Supplies CC, Durban, South Africa) [17]. Flocculation activity was calculated according to the equation

$$
\text { Flocculation activity }(\mathrm{FA}) \%=\frac{A-B}{A} \times 100
$$

where $A$ is the optical density of the control at $550 \mathrm{~nm}$ and $\mathrm{B}$ is the optical density of the sample at $550 \mathrm{~nm}$.

\subsection{Optimization of S1, S2, and S3 in Flocculation Activity}

Optimization of core-shell nanoparticles was achieved by varying various parameters such as dosage, temperature, $\mathrm{pH}$, and cations against a kaolin clay solution. To evaluate the dosage effect $0.2-0.8 \mathrm{mg} / \mathrm{mL}$ concentrations were prepared. The dosage that resulted in the highest flocculation activity was used for subsequent experiments. Trivalent, divalent, and monovalent cations were evaluated for their effect on flocculation activity. Thermostability of the material was verified by varying the temperature $\left(60,80\right.$, and $\left.100{ }^{\circ} \mathrm{C}\right)$. Finally, evaluation of the effect of $\mathrm{pH}$ was conducted by changing the $\mathrm{pH}$ to 3,7 , and 11 , which represented acidic, neutral, and alkaline conditions, respectively. 
All these parameters were varied in order to establish conditions that favored the optimal flocculation activity [18].

\subsection{Dye Removal by Core-Shell Nanoparticles}

Dyes such as safranin, methylene blue, methylene orange, and malachite green were used to evaluate the removal efficiency of core-shell nanoparticles. Core-shell nanoparticles of $0.2 \mathrm{mg}$ were dissolved in $50 \mathrm{~mL}$ distilled water, after which $2 \mathrm{~mL}$ of nanoparticle solution was mixed with dye solution $(4 \mathrm{~g} / \mathrm{L})$ and the mixture shaken for a minute and allowed to stand at room temperature for $5 \mathrm{~min}$. Each dye solution was measured at a maximum wavelength and all the experiments were conducted in triplicate. The supernatant was analyzed using a Pharo 100 Spectrophotometer ${ }^{\circledR}$. The following formula was used for calculating the removal efficiency (RE), i.e.,

$$
\operatorname{RE}(\%)=\frac{C i-C f}{C i} \times 100
$$

where $C_{i}$ is the initial value before addition of nanoparticles and $\mathrm{C}_{f}$ is the value after the treatment with core-shell nanoparticles.

\subsection{Characterization of $S 1, S 2$, and $S 3$}

4.5.1. Morphological Studies and Elemental Analysis of S1, S2, and S3

A scanning electron microscope JEOL JSM 6100 SEM with Bruker Quantax Esprit software (JEOL USA, Inc., Peabody, Massachusetts 01960, USA) equipped with EDX techniques was used for the morphological and compositional information of the samples S1, S2, and S3. SEM images were taken using a tungsten (W) filament operated at an emission current and accelerator voltage of $100 \mu \mathrm{A}$ and $10 \mathrm{kV}$, respectively. SEM samples were prepared by placing a small quantity of the material on double-sided carbon tape stuck on a copper stub and coated with carbon (JEOL USA, Inc., Peabody, MA 01960, USA) [19].

\subsubsection{FT-IR and X-Ray Diffraction Analysis of S1, S2, and S3}

FT-IR spectroscopy was used to identify and confirm the functional groups present in the bioflocculants using a Bruker Tensor 27 FT-IR spectrometer (Bruker, Gauteng, South Africa). FT-IR spectra were recorded for the dry powder samples with a resolution of $4 \mathrm{~cm}^{-1}$ in the range $4000-200 \mathrm{~cm}^{-1}$.

The crystallinity of the synthesized samples was studied using a Bruker D8 Advance diffractometer (Bruker, Johannesburg, South Africa) equipped with $\mathrm{Cu}-\mathrm{K} \alpha$ radiation $(\lambda=1.5406 \AA)$ at $40 \mathrm{kV}, 40 \mathrm{~mA}$ at room temperature. The dry samples were placed on a sample holder and the diffraction patterns were recorded from $5^{\circ}$ to $90^{\circ}$.

\subsubsection{Thermogravimetric Analysis of S1, S2, and S3}

Thermogravimetric analysis was performed on the synthesized samples using a Perkin-Elmer Thermal Analysis Pyris 6 TGA (PerkinElmer, Inc., Waltham, MA 02451, USA). High temperatures ranging $22^{\circ}$ to $900^{\circ} \mathrm{C}$ were used to heat the bioflocculants at a constant rate of ramping of $10^{\circ} \mathrm{C} \mathrm{min}-1$ and under a constant flow of nitrogen gas [20].

\subsection{Statistical Analysis}

The experimental data was collected in triplicate and error bars in the figures represent the standard deviation of the data. All data were subjected to one-way variance analysis using graph pad prism version 6.1, where a significant level of $p<0.05$ was used. 


\section{Conclusions}

In this work, characterization of bioflocculant synthesized Fe@Cu core-shell nanoparticles was achieved by the use of Fourier-transform infrared spectroscopy, X-ray diffractometry, and scanning electron microscopy. The FTIR analysis revealed the presence of hydroxyl, amine, and amide groups in the samples. XRD analysis showed deep peaks at $2 \theta \sim 35^{\circ}, 40^{\circ}$, and $65^{\circ}$ in S1. Contrary to this, it was noted that the strongest peaks were at $2 \theta \sim 35^{\circ}, 45^{\circ}, 65^{\circ}$, and $77^{\circ}$ for S2. In S3, the strongest peaks were observed at $2 \theta \sim 22^{\circ}$ and $30^{\circ}$, and morphological studies revealed an amorphous-like structure for all three samples. When evaluated for flocculation activity the synthesized samples (S1, S2, and S3) were effective at a low dosage concentration of $2 \mathrm{mg} / \mathrm{mL}$, were thermostable, and could flocculate at all $\mathrm{pH}$. Cations are not necessary in the flocculation process while using these samples. All three samples revealed some remarkable properties for dye removal as the removal efficiency was above $89 \%$ for all dyes tested. The synthesized Fe@Cu core-shell nanoparticles could remove nutrients such as total nitrogen and phosphate in both domestic wastewater and Mzingazi river water. Furthermore, high removal efficiencies for $\mathrm{COD}$ and $\mathrm{BOD}$ were also observed, with $\mathrm{S} 3$ being the most effective sample, followed by $\mathrm{S} 2$, and $\mathrm{S} 1$ being the least effective.

Supplementary Materials: The following are available online at http://www.mdpi.com/2073-4344/10/7/755/s1, Figure S1: UV spectra of Fe@Cu core-shell nanoparticles, Figure S2: TEM images of Fe@Cu core-shell nanoparticles, Figure S3: TGA analysis of samples (a) S1 (b) S2 and (c) S3.

Author Contributions: Conceptualization, A.K.B. and V.S.R.P.; formal analysis, N.G.D. and V.S.R.P.; investigation, N.G.D.; supervision, A.K.B., V.S.R.P., and S.J.S.E.; writing—original draft, N.G.D.; writing—review and editing, V.S.R.P. and S.J.S.E. All authors have read and agreed to the published version of the manuscript.

Funding: Rajasekhar Pullabhotla would like to acknowledge the National Research Foundation (NRF, South Arica) for their financial support in the form of the Incentive Fund Grant (grant no. 103691) and the Research Developmental Grant for Rated Researchers (112145).

Acknowledgments: Nkosinathi Dlamini would like to acknowledge the Council for Scientific and Industrial Research (CSIR, South Africa) for their financial assistance in the form of a Ph.D. bursary. The authors would like to acknowledge the Electron Microscopy Unit at the University of KwaZulu-Natal, Westville campus, for providing support by letting us use the TEM and SEM-EDX facilities for the characterization of nanomaterials. Rajasekhar Pullabhotla would like to acknowledge the National Research Foundation (NRF, South Arica) for their financial support in the form of the Incentive Fund Grant (grant no. 103691) and the Research Developmental Grant for Rated Researchers (112145).

Conflicts of Interest: The authors declare no conflict of interest.

\section{References}

1. Tiwari, D.K.; Behari, J.; Sen, P. Application of nanoparticles in wastewater treatment 1. World Appl. Sci. J. 2008, 3, 417-433.

2. Exley, C.; Korchazhkina, O.; Job, D.; Strekopytov, S.; Polwart, A.; Crome, P. Non-invasive therapy to reduce the body burden of aluminium in Alzheimer's disease. J. Alzheimer's Dis. 2006, 10, 17-24. [CrossRef] [PubMed]

3. Yang, Z.-H.; Huang, J.; Zeng, G.-M.; Ruan, M.; Zhou, C.-S.; Li, L.; Rong, Z.-G. Optimization of flocculation conditions for kaolin suspension using the composite flocculant of MBFGA1 and PAC by response surface methodology. Bioresour. Technol. 2009, 100, 4233-4239. [CrossRef]

4. Sankar, R.; Manikandan, P.; Malarvizhi, V.; Fathima, T.; Shivashangari, K.S.; Ravikumar, V. Green synthesis of colloidal copper oxide nanoparticles using Carica papaya and its application in photocatalytic dye degradation. Spectrochim. Acta Part A Mol. Biomol. Spectrosc. 2014, 121, 746-750. [CrossRef]

5. Dlamini, N.G.; Basson, A.K.; Pullabhotla, V.S.R. Optimization and Application of Bioflocculant Passivated Copper Nanoparticles in the Wastewater Treatment. Int. J. Environ. Res. Public Health 2019, 16, 2185. [CrossRef]

6. Xu, P.; Zeng, G.M.; Huang, D.L.; Feng, C.L.; Hu, S.; Zhao, M.H.; Lai, C.; Wei, Z.; Huang, C.; Xie, G.X. Use of iron oxide nanomaterials in wastewater treatment: A review. Sci. Total Environ. 2012, 424, 1-10. [CrossRef] [PubMed] 
7. Maliehe, T.S.; Basson, A.K.; Dlamini, N.G. Removal of Pollutants in Mine Wastewater by a Non-Cytotoxic Polymeric Bioflocculant from Alcaligenes faecalis HCB2. Int. J. Environ. Res. Public Health 2019, 16, 4001. [CrossRef]

8. Sworska, A.; Laskowski, J.; Cymerman, G. Flocculation of the Syncrude fine tailings: Part I. Effect of pH, polymer dosage and Mg2+ and Ca2+ cations. Int. J. Miner. Process. 2000, 60, 143-152.

9. Zaki, S.A.; Elkady, M.F.; Farag, S.; Abd-El-Haleem, D. Characterization and flocculation properties of a carbohydrate bioflocculant from a newly isolated Bacillus velezensis 40B. J. Environ. Biol. 2013, 34, 51. [PubMed]

10. Gao, X.; Wei, L.; Yan, H.; Xu, B. Green synthesis and characteristic of core-shell structure silver/starch nanoparticles. Mater. Lett. 2011, 65, 2963-2965. [CrossRef]

11. Zheng, Y.; Ye, Z.-L.; Fang, X.-L.; Li, Y.-H.; Cai, W.-M. Production and characteristics of a bioflocculant produced by Bacillus sp. F19. Bioresour. Technol. 2008, 99, 7686-7691. [CrossRef] [PubMed]

12. Giri, S.S.; Harshiny, M.; Sen, S.S.; Sukumaran, V.; Park, S.C. Production and characterization of a thermostable bioflocculant from Bacillus subtilis F9, isolated from wastewater sludge. Ecotoxicol. Environ. Saf. 2015, 121, 45-50. [CrossRef] [PubMed]

13. Zaimy, M.; Jebali, A.; Bazrafshan, B.; Mehrtashfar, S.; Shabani, S.; Tavakoli, A.; Hekmatimoghaddam, S.; Sarli, A.; Azizi, H.; Izadi, P. Coinhibition of overexpressed genes in acute myeloid leukemia subtype M2 by gold nanoparticles functionalized with five antisense oligonucleotides and one anti-CD33 (+)/CD34 (+) aptamer. Cancer Gene Ther. 2016, 23, 315. [CrossRef] [PubMed]

14. Ali, H. Biodegradation of Synthetic Dyes-A Review. Water Air Soil Pollut. 2010, 213, 251-273. [CrossRef]

15. Davis, A.P.; Shokouhian, M.; Sharma, H.; Minami, C. Water quality improvement through bioretention media: Nitrogen and phosphorus removal. Water Environ. Res. 2006, 78, 284-293. [CrossRef] [PubMed]

16. Yu, X.; Li, J.; Shi, T.; Cheng, C.; Liao, G.; Fan, J.; Li, T.; Tang, Z. A green approach of synthesizing of Cu-Ag core-shell nanoparticles and their sintering behavior for printed electronics. J. Alloys Compd. 2017, 724, 365-372. [CrossRef]

17. Kurane, R.; Toeda, K.; Takeda, K.; Suzuki, T. Culture conditions for production of microbial flocculant by Rhodococcus erythropolis. Agric. Biol. Chem. 1986, 50, 2309-2313.

18. Agunbiade, M.; Pohl, C.; Ashafa, O. Bioflocculant production from Streptomyces platensis and its potential for river and waste water treatment. Braz. J. Microbiol. 2018, 49, 731-741. [CrossRef] [PubMed]

19. Zhong, C.; Cao, G.; Rong, K.; Xia, Z.; Peng, T.; Chen, H.; Zhou, J. Characterization of a microbial polysaccharide-based bioflocculant and its anti-inflammatory and pro-coagulant activity. Colloids Surf. B Biointerfaces 2018, 161, 636-644. [CrossRef] [PubMed]

20. Dlamini, N.G.; Basson, A.K.; Pullabhotla, V.S.R. Biosynthesis and Characterization of Copper Nanoparticles Using a Bioflocculant Extracted from Alcaligenis faecalis HCB2. Adv. Sci. Eng. Med. 2019, 11, 1-7. [CrossRef] 